\title{
O significado de cuidar do paciente obeso para um grupo de enfermeiras
}

\author{
The meaning of providing caring to obese patients to a group of nurses
}

Significado de cuidar del paciente obeso para un grupo de enfermeras

Emilly Souza Marques ${ }^{1}$, Géssyca Cavalcante de Melo $^{2}$, Regina Maria dos Santos ${ }^{3}$

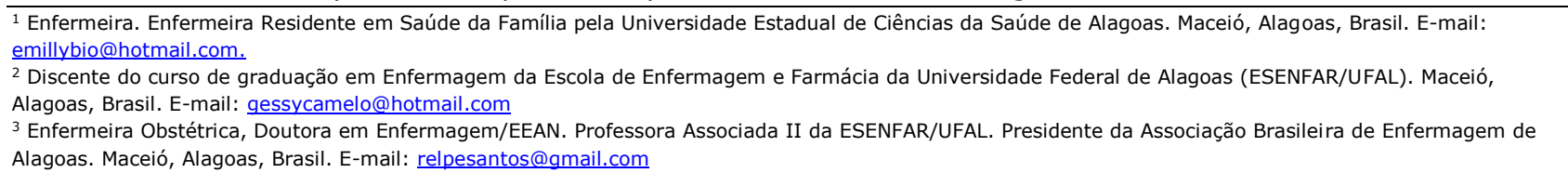
Alagoas. Maceió, Alagoas, Brasil. E-mail: relpesantos@gmail.com

\section{RESUMO}

Trata-se de um estudo qualitativo realizado com seis enfermeiras de um hospital público, cujo objetivo foi descrever o significado de cuidar do paciente obeso para essas profissionais. As informações foram produzidas mediante entrevista gravada e transcrita, utilizando roteiro semiestruturado. Os dados foram organizados por temas extraídos das falas exaustivamente lidas e o Interacionismo Simbólico foi adotado para interpretação dos achados. Os resultados gerados a partir do processo analítico foram organizados em torno dos seguintes temas: Ser obeso é estar acima, não é saudável; Cuidar de obesos é uma questão estrutural; Pacientes obesos dão trabalho, inspiram cuidados, nada de mais; Cuidar de obesos exige trabalho em equipe. Os significados apreendidos podem interferir na assistência prestada, porém as enfermeiras reconhecem a necessidade do trabalho em equipe para cuidar integralmente. É possível que os significados encontrados nesta pesquisa possam ser modificados positivamente, contribuindo para um cuidado de Enfermagem ao obeso livre de discriminações.

Descritores: Obesidade; Cuidados de Enfermagem; Assistência Hospitalar.

\section{ABSTRACT}

This qualitative study was performed with six nurses of a public hospital, with the objective to describe their view of the meaning of providing care to obese patients. Interviews were conducted using a semi-structured script. The data were organized under themes extracted from the subjects' statements, after being thoroughly read. Symbolic Interactionism was adopted to interpret the findings. The results from the analysis were organized under the following themes: Being obese is excessive, it is not healthy; Providing care to the obese is a structural issue; Obese patients are troublesome, they require care, no big deal; Providing care to the obese requires teamwork. The grasped meanings can interfere in the care provided. The nurses, however, recognize the need to work as a team to deliver comprehensive care. Making positive changes to the meanings found in this study is possible, thus, contributing to providing prejudice-free nursing care to obese patients.

Descriptors: Obesity; Nursing Care; Hospital Care.

\section{RESUMEN}

Estudio cualitativo realizado con seis enfermeras de un hospital público, objetivando describir el significado de cuidar del paciente obeso en dichas profesionales. Se generó la información mediante entrevistas grabadas y transcriptas, utilizándose guión semiestructurado. Los datos fueron organizados por temas, extraídos de los testimonios leídos exhaustivamente. Se adoptó el Interaccionismo Simbólico para interpretar los hallazgos. Los resultados generados a partir del proceso analítico fueron organizados en torno a los siguientes temas: Ser obeso es estar excedido, no es saludable; Cuidar de obesos es una cuestión estructural; Los pacientes obesos dan trabajo, inspiran cuidados, no es problema; Cuidar de obesos requiere de trabajo en equipo. Los significados aprendidos pueden interferir en la atención brindada, aunque las enfermeras reconocen la necesidad del trabajo en equipo para cuidar integralmente. Es posible que los significados encontrados en el estudio sean modificados positivamente, contribuyendo a un cuidado de Enfermería libre de discriminaciones hacia el obeso.

Descriptores: Obesidad; Atención de Enfermería; Atención Hospitalaria. 


\section{INTRODUÇÃO}

A obesidade é uma doença crônica determinada por causas múltiplas e complexas que levam ao distúrbio alimentar, caracterizado por ser um quadro prolongado de ingestão calórica maior do que o gasto energético, no qual há acúmulo excedente nas células adiposas com consequente aumento de gordura corporal e balanço positivo(1-2). Atualmente, no Brasil, a obesidade vem se constituindo como um problema de saúde pública(3), haja vista a sua alta prevalência, principalmente entre jovens ${ }^{(4)}$, como comprova um estudo epidemiológico que vem sendo realizado com dados desde 2006(5). Em Maceió, capital nordestina, este fenômeno já se apresenta como motivo de preocupação, como evidenciam os dados de pesquisa publicada em $2010^{(6)}$.

A prevalência da obesidade vem aumentando de forma crescente em todas as faixas etárias, em todos os estratos sociais, tanto em países desenvolvidos quanto naqueles em desenvolvimento, o que a torna epidêmica em alguns países(6). No Brasil, principalmente, no Nordeste vem configurando uma transição nutricional, dado o maior acesso da população aos alimentos ${ }^{(6)}$, sem que tenha havido ações de educação alimentar, um dos determinantes de sobrepeso.

Além de consequências físicas, a doença resulta, principalmente, em desconfortos psicossociais, o que muitas vezes são decorrentes dos estigmas sociais em relação a essa situação. Sem dúvida, essas consequências psicossociais da obesidade também estão ligadas à cultura atual que considera o corpo gordo feio e inaceitável(7), reafirmando a importância de realizar estudos que abordem esta questão.

No ambiente hospitalar, a interação com o indivíduo obeso geralmente é estabelecida com maior frequência pelos profissionais de enfermagem, cabendo, especialmente ao enfermeiro, o planejamento do cuidado a ser prestado a estes pacientes, fato que contribui para que esse profissional institua uma relação mais próxima com ele e conheça suas necessidades a fim de assisti-lo( ${ }^{(8)}$. Também o enfermeiro é o profissional que faz a gestão deste cuidado e conhece a sua equipe e as suas condições de trabalho, ouvindo muitas vezes as queixas dos seus coordenados.

Neste sentido, estudo revelou a baixa empatia que a equipe de enfermagem demonstra no tratamento e relação com o paciente obeso, o que, somado à inexistência de equipamentos específicos direcionados a esse, contribui na construção de um ambiente psicológico insatisfatório, interferindo na sua vida, atitudes e decisões $^{(5)}$, ao mesmo tempo em que pode estar interferindo na qualidade do cuidado prestado a estes pacientes.

A vivência das pesquisadoras em cuidar de pacientes com tais características permitiu observar que o comportamento dos membros da equipe de enfermagem se modificava em razão das dificuldades maiores ou menores que tinham, para prestar assistência à pessoa obesa. Porém, seu comportamento também se modificava a depender do humor do paciente. Estas observações conduziram à formulação das seguintes perguntas de pesquisa: Quais significados os enfermeiros atribuem ao ato de cuidar do paciente obeso? Os significados atribuídos interferem na prestação da assistência de enfermagem a esse tipo de paciente? O presente estudo teve como objetivo descrever o significado de cuidar do paciente obeso para um grupo de enfermeiras.

\section{METODOLOGIA}

Pesquisa qualitativa de caráter descritivo desenvolvido com enfermeiras atuantes no turno diurno dos setores da clínica médica, clínica cirúrgica e Unidade de Terapia Intensiva (UTI) Geral de um hospital de ensino localizado em Maceió-Alagoas, escolhido por ser uma unidade de referência para tratamento bariátrico. Os setores foram selecionados pela observação cotidiana de que são nestes onde ocorre o maior número de internações de adultos obesos, favorecendo o contato $\mathrm{da}(\mathrm{o})$ enfermeira(o) com esse tipo de paciente.

Os sujeitos foram enfermeiras que voluntariamente se propuseram a participar do estudo, atendendo aos seguintes critérios de inclusão: estarem no serviço há pelo menos cinco anos, tendo acumulado experiência para falar sobre a questão; estarem lotadas nos serviços selecionados, favorecendo a experiência de cuidar de obesos e estarem como coordenadoras dos serviços, responsáveis, portanto, pela gestão do cuidado. Férias e licenças excluíram sujeitos, bem como a existência de qualquer tipo de dificuldade de comunicação. Nestas condições, os seis sujeitos pertenceram ao sexo feminino, o que não é estranho, pois cerca de $80 \%$ dos enfermeiros do hospital são mulheres. Além disso, os homens estão mais frequentemente lotados no turno noturno.

Para a execução da pesquisa, foi solicitada a autorização da direção da instituição por meio de assinatura de um termo de autorização em duas vias. Já para a inclusão voluntária das participantes, foi feito um trabalho de aproximação com as mesmas e realizado um convite para que participassem do estudo. Àquelas que aceitaram, foi solicitada a assinatura do Termo de Consentimento Livre e Esclarecido. A pesquisa respeitou 
as diretrizes da Resolução n.196/96 do Conselho Nacional de Saúde que envolve pesquisa com seres humanos, sendo somente iniciada após o projeto ter sido aprovado pelo Comitê de Ética da Universidade Federal de Alagoas (UFAL) sob o protocolo no 23065.018656/2009-7s.

Como instrumento para as entrevistas áudiogravadas foi utilizado um roteiro semiestruturado com questões que permitiram caracterizar os sujeitos, identificar sua situação quanto ao tempo de trabalho e coletar informações que respondessem aos objetivos da pesquisa, como: conceito de obesidade considerado pelas enfermeiras, significado da admissão de um paciente obeso, sentimentos e expressões da equipe de enfermagem ao cuidar do mesmo e existência de dificuldades ou diferenças na assistência quando comparadas às intervenções prestadas aos outros pacientes internados. Os dados foram coletados entre maio e julho de 2011, após agendamento prévio de data e local para as entrevistas, conforme disponibilidade dos sujeitos.

Os documentos resultantes da transcrição das entrevistas foram lidos exaustivamente até identificar os sentidos e as falas que mostrassem os significados do cuidar de obesos para essas enfermeiras. A análise das falas buscou relacioná-las aos objetivos da pesquisa e organizá-las em agrupamentos descritivos e em temas derivados do conteúdo dos dados, os quais serão apresentados neste estudo. Os resultados encontrados foram discutidos com a literatura que envolve as temáticas.

A partir do que foi observado com as informações levantadas, foi pertinente adotar o Interacionismo Simbólico como referencial teórico, sob a perspectiva de Blumer $^{(9)}$, que apresenta três premissas fundamentais, a saber: o ser humano age em relação às coisas baseado nos sentidos que essas têm para ele; o significado das coisas se origina da interação social que o indivíduo estabelece com os outros; os significados são manipulados e modificados através de um processo interpretativo usado pela pessoa ao lidar com as coisas e situações que ela encontra ${ }^{(9)}$. Essas premissas conduziram a busca das falas que melhor apresentariam o pensamento das enfermeiras estudadas.

Para assegurar o anonimato das participantes em relação às falas apresentadas neste artigo, as mesmas foram identificadas pela letra $E$ (inicial de enfermeira) acrescida do algarismo numérico correspondente à sequência da realização das entrevistas.

\section{RESULTADOS E DISCUSSÃO}

Participaram do estudo seis enfermeiras com idades entre 30 e 55 anos. A maioria é casada, com renda aproximada de oito salários mínimos, tempo de formadas entre dois e 31 anos, tempo de trabalho na área e tempo de trabalho no hospital entre cinco e 29 anos e tempo de trabalho nos setores até seis anos. Todas possuem especialização e participaram de treinamento na unidade hospitalar, em período inferior a um ano.

A análise dos dados sob a luz de Blumer $^{(9)}$ permitiu a compreensão dos significados atribuídos ao cuidado ao paciente obeso construído a partir de suas experiências. Assim, identificaram-se fenômenos descritos segundo os conceitos que emergiram das informações, de acordo com os elementos que compõem o processo. Os temas a seguir revelam os significados apreendidos das falas dos sujeitos:

\section{Ser obeso é estar acima, não é saudável, é visível!}

Ao considerar que ser obeso é estar acima, é não estar saudável e se deixa ver, as enfermeiras atribuíram à obesidade o caráter de doença visível, o que é de se esperar, pois no meio científico é assim que a mesma é vista $^{(1-3,10)}$. Os sujeitos, para significar a obesidade, se respaldaram na ciência, como pode ser visto nos subtemas:

\section{Obeso é estar acima de sua capacidade}

Para os sujeitos entrevistados, ser alguém acima de sua capacidade significa estar além do Índice de Massa Corpórea (IMC) normal. Porém, não se trata apenas de uma medida fisiológica, é estar acima do peso, muito acima do peso, muito superior ao esperado, ao ponto de ser notável visivelmente:

(...) quando está acima do peso, muito acima do peso, muito acima do peso ideal. Está além da capacidade dele. Ser obeso é visível. Julgamos o que vemos. (E5)

(...) obeso é aquele que tem peso muito superior ao esperado. Normalmente com IMC aproximadamente acima de 25. (E6)

Então, realmente é uma pessoa que a gente vê, é visual.(E4)

Cientificamente, sabe-se que o principal método técnico de classificação da obesidade atual ainda é o cálculo do IMC. Dessa forma, ao utilizá-lo, é possível já considerar como pessoa obesa aquela que possui IMC maior que 30 , ou seja, acima do valor aceitável ${ }^{(1)}$. 
Entretanto, a obesidade é considerada como um estado destoante dos padrões de normalidade cultural, ou seja, o obeso é anormal pois difere do ideal de beleza do corpo construído pela sociedade. Este sinal é dado pela abundância de gordura corporal e é facilmente observado, tornando seu corpo algo visível, diferente diante das pessoas $^{(10)}$.

Ao associar a obesidade com o valor do IMC, as enfermeiras consideram o aspecto estritamente técnico da definição apreendida durante sua formação acadêmica. Porém, observa-se que através das relações sociais que possibilitam sua interação como pessoas no mundo e não só como profissionais, é possível a construção de símbolos, sendo esses o que vemos e que permitem a atribuição de significados $^{(9)}$.

Para o Interacionismo Simbólico, os significados são modificados quando as pessoas, ao considerá-los conscientemente, interpretam e selecionam, transformando-os nos seus próprios significados ${ }^{(9)}$. Para os sujeitos da pesquisa, o símbolo da obesidade, que é explicitado pela visibilidade, significa o estar 'acima' em todos os aspectos diante das outras pessoas, é ser o diferencial, sendo estes seus próprios significados.

Essa perspectiva leva a refletir sobre o fato de que, apesar de ser esperado que as enfermeiras busquem diferenças entre o corpo magro e o obeso devido à sua interação com a sociedade e até por sua rotina profissional, o significado do ser obeso para a equipe que é atribuído pela observação estética da pessoa e de seus aspectos, pode vir a ser modificado quando se utilizam critérios apropriados para a construção do significado do ser obeso, uma vez que, a depender da maneira como este é atribuído, pode afetar positiva ou negativamente na forma de se prestar assistência.

Ao caracterizar o obeso como uma pessoa que se encontra acima de sua capacidade e além do IMC considerado normal, as enfermeiras podem estar atribuindo a essas pessoas o significado de não serem saudáveis, o que pode ser notado mais claramente no seguinte subtema.

\section{Obeso não é saudável}

Ser alguém não saudável significa possuir um problema de saúde. Mais que isso, é ser alguém para quem o mundo não está adaptado. Para os sujeitos, a obesidade é uma patologia causada por diversos fatores, pois "ninguém é obeso do nada" (E2). Esta condição traz consequências que dificultam à pessoa exercer algumas atividades, tornando-a limitada no sentido físico e à adaptação:
Vejo como uma pessoa não tão saudável. (E6)

(...)a obesidade já é considerada uma doença. Ser obeso acarreta dificuldades ou impossibilidades de exercer atividades que os magros fazem com facilidade. (E1)

Ninguém é obeso do nada, tem o histórico hormonal, familiar, psicológico. O obeso é uma pessoa com limitações de adaptação porque o mundo não está adaptado para o obeso e o obeso, bichinho, até que está adaptado pro mundo. (E2)

A gente percebe que normalmente tem limitação física. (E5)

Ao entenderem que a pessoa obesa não é tão saudável, as enfermeiras mais uma vez recorreram aos conhecimentos científicos, pois a obesidade é considerada um dos mais graves problemas de Saúde Pública inseridos no grupo das Doenças Crônicas Não-Transmissíveis, que vem crescendo ao longo dos anos mundialmente ${ }^{(2)}$.

Apesar de suas causas ainda não serem elucidadas, incluem-se aspectos ambientais, socioeconômicos, comportamentais, psicossociais, endócrinos e genéticos. As consequências metabólicas abrangem as comorbidades endócrinas, cardiovasculares, respiratórias, gastrintestinais, ginecológicas/genito-urinárias e câncer ${ }^{(11)}$.

Afirma-se ainda que a obesidade acarreta limitações físicas devido ao excesso de peso, prejudicando o desenvolvimento até mesmo de ações do cotidiano como as atividades domésticas, cuidados com a família, o ato de fazer higiene pessoal, vestir-se, caminhar, subir uma escada e relacionar-se sexualmente ${ }^{(11)}$.

Além disso, o obeso carrega a responsabilidade de se adaptar a determinados lugares públicos que, em sua maioria, somente possuem cadeiras que não suportam muito peso; catracas estreitas e roupas à venda com tamanho inadequado para seu porte físico, entre outros contextos que afetam a sua qualidade de vida(3).

É nesse sentido que as enfermeiras, a partir da interação que possuem como profissionais com essas pessoas hospitalizadas constroem como significado da obesidade uma doença, mas que vai além da própria vontade do obeso ou do aspecto biológico, envolvendo outras esferas, especialmente as psicológicas e familiares. Apesar deste significado remeter ao entendimento da amplitude da definição de obesidade, é possível notar na prática que os profissionais de saúde normalmente visam apenas a necessidade de um tratamento clínico para esta doença, contrapondo o que consideram.

Observa-se ainda que as enfermeiras provavelmente se reportam tanto ao significado atribuído pela sociedade, 
assim como aos seus próprios significados acerca da pessoa obesa, pois em suas falas comparam a facilidade com que os magros realizam certas atividades do cotidiano em relação às limitações que o obeso possui, ou seja, reforçam o significado de destoante diante do padrão imposto $^{(10)}$.

Vale ressaltar que ao reconhecer o obeso necessariamente como portador de limitações de adaptação, as enfermeiras podem estar agindo com menosprezo ao percebê-lo como "bichinho" (E2), corroborando com o Interacionismo Simbólico ao afirmar que as pessoas desencadeiam uma ação frente às coisas, não de uma forma mecânica, mas consoante aos significados que as coisas têm para elas ${ }^{(9)}$.

Assim, ao considerar o obeso como alguém doente, as enfermeiras podem estar subestimando a pessoa, física ou emocionalmente, tornando o cuidar um ato de caridade e não algo inerente ao processo de trabalho da enfermagem. Ao cuidar como caridade, o profissional retira o caráter científico e imprime o poder de cuidar na sua própria perspectiva e não de acordo com a necessidade real do ser cuidado. Assim sendo, revela-se que o significado atribuído ao obeso de pessoa não saudável, não é oriundo apenas do conhecimento científico, mas de suas próprias convicções pessoais sobre essas pessoas.

Além disso, ao referirem que o mundo não se encontra adaptado para essas pessoas no cotidiano, as enfermeiras podem estar se remetendo também às dificuldades da estrutura do ambiente hospitalar para o acolhimento desse paciente, fato que se encontra explícito no tema a seguir.

\section{Cuidar de obesos é questão de estrutura}

Ao considerar que cuidar de pacientes obesos é questão estrutural, as enfermeiras afirmam ser relevante a existência de condições mínimas para cuidar. Isto requer materiais adaptados ao seu porte físico, assim como maior número de pessoas para exercer algumas atividades de maior força física:

Você tem que dar condições para cuidar dele. Tem que ter cama, cadeira, roupa, fralda que suporte seu corpo. Vou precisar de dois auxiliares pra o banho. (E5)

Quando vamos transportar ou mobilizar no leito, sempre precisamos de outra pessoa, duas ou três. Uma pessoa só não pode tratar de um obeso sozinho. (E1)

Na minha escala eu já não posso colocar uma pessoa, eu tenho que pensar em mais gente pra colocar com ele. (E4)
Em seus discursos, as enfermeiras entrevistadas revelaram que a assistência ao paciente obeso exige condições especiais, fato que encontra respaldo na literatura, denotando a preocupação em justificarem seus significados cientificamente. Desse modo, sabe-se que os hospitais devem dispor de acessos especiais adequados, como rampas e portas; vasos sanitários, balança e cadeiras de rodas com capacidade mínima para $300 \mathrm{~kg} \mathrm{e}$, no mínimo, três leitos com cama acionável por controle, entre outros itens ${ }^{(12)}$.

Além de equipamentos hospitalares, para cuidar do paciente obeso é necessário mais pessoal, em especial, de enfermagem. Os recursos humanos devem ser considerados, pois o peso do paciente é uma grande limitação para a equipe e dificulta toda a assistência em ações simples do cotidiano hospitalar ${ }^{(11)}$.

Ao atribuir o significado do obeso como uma pessoa muito acima do peso, muito superior ao esperado, algo exagerado, alguém não saudável, através do Interacionismo Simbólico, pode-se associar que as enfermeiras do estudo já vislumbram a existência de certas atividades que necessitarão de maior força física por parte da equipe e, como consequência, de mais pessoal dentre o quadro de funcionários, ou seja, percebem a pessoa obesa como aquela que demanda mais necessidades que os outros pacientes.

Esta compreensão nos faz refletir que as ações das enfermeiras deveriam ser direcionadas visando o obeso como portador de direitos e não como sujeito limitante. Desse modo, as mesmas justificam o fato dos obesos serem pacientes que dão mais trabalho porque a equipe não dispõe de recursos humanos suficientes $e$ equipamentos específicos para cuidar desse paciente, como é apresentado no tema a seguir.

\section{Pacientes obesos dão trabalho, inspiram cuidado... nada demais!}

Os sujeitos destacam o fato de que cuidar de pessoas obesas requer um desgaste físico grande e consideram que esse paciente possui especificidades orgânicas que exigem cuidados de enfermagem diferenciados. Todavia, uma das profissionais entrevistadas percebe que 0 cuidado em si faz parte de sua prática, independentemente do indivíduo que o recebe, fato elucidado com maior clareza nos subtemas a seguir:

\section{Cuidar do paciente obeso é ter mais trabalho}

Para os sujeitos, ter mais trabalho significa atuar além da rotina diária, ou seja, é ter desgaste físico e emocional, tornando o cuidar cansativo, principalmente para um 
grupo de profissionais do sexo feminino com menor força e que não pode "pegar peso" (Enfa 2). Isto contribui para a não aceitação de funcionários para cuidar do paciente:

(...) a gente vai ter um pouco mais de trabalho em relação à parte física e emocional, pois é um paciente pesado. $O$ trabalho vai ser um pouco maior. Ninguém quer porque o paciente é pesado, então ninguém quer cuidar do paciente obeso. (E4)

O funcionário tem dificuldade de trabalhar com o obeso porque a gente, na maioria das vezes, trabalha com mulheres, pessoas que não podem pegar muito peso porque tem limitações físicas decorrentes do trabalho. (E2)

É uma dificuldade achar alguém que queira cuidar do paciente obeso. (E6)

Ao elucidarem o trabalho de cuidar de pacientes obesos como sendo algo cansativo, associado com as afirmações acerca da falta de estrutura hospitalar específica para a assistência a esses pacientes, as enfermeiras entrevistadas atribuem essa dificuldade às limitações físicas decorrentes da rotina da prática em enfermagem, denotando respaldo na literatura no que se refere aos riscos ocupacionais no contexto hospitalar.

As condições de trabalho ofertadas pelos hospitais, as tarefas de enfermagem peculiares a cada tipo de indivíduo com diferentes necessidades e a carência de recursos humanos e materiais, especialmente quando se trata da assistência prestada a um obeso,são fatores que contextualizam a situação laboral do pessoal de enfermagem mundialmente, fato que pode acarretar sérios desgastes físicos e emocionais aos profissionais, uma vez que ao cuidar de obesos é necessário atentar para sua dificuldade de aceitar restrições alimentares e investir no resgate de sua auto-imagem ${ }^{(10,12)}$.

Com o propósito de ressignificar o cuidado ao paciente obeso, a enfermeira, como portadora de conhecimentos apropriados, pode interagir na relação de saúde-doença do paciente, demonstrando que o cuidar é uma ação humana, transpessoal e política. Assim, o que se espera do profissional de enfermagem é a aceitação da prestação da assistência a todos os pacientes sem distinção, já que esse ato inclui dimensões além das biológicas, exigindo relacionamento interpessoal, toque e afetividade ${ }^{(12)}$.

Contudo, ao retomarmos o significado que as enfermeiras atribuem ao paciente obeso, relacionando-o à inadequação do ambiente hospitalar e à especificidade do processo de cuidar no sentido de ser mais desgastante, percebe-se a cadeia consequente de significados e ações que se pode denotar através do Interacionismo Simbólico, pois ao definir uma situação, a pessoa planeja uma resposta, isto é, a ação com base no significado que foi atribuído por ela, às coisas com as quais interagiu ${ }^{(9)}$.

A resposta planejada pelas enfermeiras aos seus significados se caracteriza pela não aceitação da equipe para cuidar do indivíduo obeso, visto que o percebem como alguém muito acima do peso, reconhecem que não possuem equipamentos para cuidar e ainda que este paciente significa desgaste, mais trabalho além do físico, desencadeando uma resposta de negação a estes fatos, como é observado no próximo subtema.

\section{O paciente obeso requer mais cuidado}

Para as profissionais entrevistadas, requerer mais cuidado significa atenção redobrada no sentido de observar mais os detalhes que se referem à alimentação, manipulação, mobilização e prevenção de úlceras por pressão e edemas, ou seja, é ter mais cuidados que um paciente que não tem peso a mais não teria:

É um paciente que requer mais atenção. O que modifica é que acrescenta mais cuidados, poissão redobrados no sentido de que a gente tem que observar mais os detalhes para manipulação, não pode passar da hora da alimentação. (E1)

Tem cuidados que um paciente que não tem peso a mais não teria e há o risco de escaras, edema. Tem que observar se está se mobilizando, dar atenção melhor por conta da alimentação, se está deambulando, pra questão pulmonar e de trombose. (E3)

Penso que é um paciente que precisa de mais cuidados. (E5)

As referências às características orgânicas atribuídas pelas enfermeiras se respaldam novamente nos seus conhecimentos científicos, pois as especificidades fisiológicas dos obesos estão relacionadas ao aumento dos volumes circulatório e plasmático, do débito cardíaco e do consumo de oxigênio proporcional à elevação do peso; redução da complacência torácica devido ao tecido gorduroso das paredes torácica e abdominal, além de diminuição da capacidade residual funcional(10).

Considerando tais especificidades e o fato de normalmente o paciente obeso estar numa clínica ou UTI devido à realização de cirurgia bariátrica, os cuidados devem ser direcionados para o acompanhamento da ingestão calórica, estimulação dos exercícios respiratórios, da mudança de decúbito e da deambulação precoce; estimulação de movimentos com os membros 
inferiores para aumentar o retorno venoso e avaliação da ferida operatória ${ }^{15)}$, como afirmaram as enfermeiras em seus discursos.

Ressalta-se a importância desse conhecimento como eixos direcionadores da prática em enfermagem, porém observa-se mais uma vez que o significado atribuído ao paciente obeso pelos sujeitos permite a interpretação de que este, por ser tão diferente, requer também mais cuidados em relação aos outros pacientes, fato justificado pelo Interacionismo Simbólico ao considerar que os significados são manipulados por meio de um processo de interpretação utilizado pelas pessoas ao lidar com situações que elas encontram ${ }^{(7)}$. Entretanto, esta perspectiva também nos faz refletir se os cuidados mencionados não são prestados a outros pacientes, pois estão inseridos dentre as necessidades humanas básicas universais. Vale salientar que o cuidar deve atender às necessidades individuais, independente de patologia ou de outros fatores $^{(13)}$.

O confronto das falas deixa entrever o incômodo por parte da equipe pela exigência de mais cuidados em relação à pessoa obesa, ato que pode recorrer em infração ética com pena de multa ou até mesmo de suspensão do exercício profissional por desrespeito ao que é estabelecido no Capítulo I, artigo 15, do Código de Ética dos Profissionais de Enfermagem, que visa como responsabilidade e dever do profissional o ato de prestar assistência a qualquer pessoa sem discriminação de qualquer natureza(14).

Contrapondo a perspectiva de negação para cuidar do paciente obeso, pode-se perceber que apenas uma das profissionais estudadas considera o ato de cuidar inerente ao ser humano, independentemente de suas características. Esta reflexão encontra respaldo no próximo subtema.

\section{Cuidar do paciente obeso não é nada demais}

Para a enfermeira entrevistada, nada demais significa dizer que o paciente obeso é como qualquer outra pessoa, independente de suas características individuais ou de sua patologia. Mais que isso, cuidar das necessidades da pessoa obesa já faz parte da rotina da equipe de enfermagem:

Cuidar de um obeso não é nada demais. É a nossa rotina, a gente já tá acostumado, faz parte do nosso perfil de pacientes. (E1)

O cuidar é a prática da enfermagem que pode ser considerada como uma forma de ser e de se relacionar, e que deve ser realizada no sentido de favorecer, manter ou melhorar o processo de viver ou morrer, proporcionando ao indivíduo a necessidade que apresenta de conforto físico, emocional e espiritual ${ }^{(15)}$.

Esta definição, a respeito do cuidar do paciente obeso, pode ser relacionada com a fala da enfermeira supracitada que contrapõe a todas as outras da pesquisa. Com base no Interacionismo Simbólico, acredita-se que o significado atribuído como algo característico de sua rotina contribui para aceitação acerca do que se faz, no caso da enfermagem, o cuidar, tendo em vista as necessidades individuais do ser humano(9).

\section{Cuidar de obesos é um problema}

Em seus depoimentos, as enfermeiras responsabilizam o paciente obeso pela dificuldade que gera ao trabalho e, devido a isso, este se torna um incômodo para a equipe de enfermagem, pois é um paciente que ninguém quer cuidar, como mostram os seguintes subtemas:

O paciente obeso dificulta o trabalho da enfermagem

Um indivíduo que dificulta o trabalho da enfermagem significa ser um paciente que não se encontra preparado psicologicamente para ser cuidado, é ser depressivo, exigente, estressado, ansioso, chato:

Eles são depressivos por conta dos traumas que trazem. Tem funcionário que diz: paciente chato. Chato quer dizer isso, porque na maioria são exigentes. Tudo o que ele já vive, pela condição dele que nada é adaptado pra ele e reclama. (E2)

Ele está estressado, ansioso, chateado e dificulta um pouco nosso cuidado. (E4)

Geralmente são pacientes que não tem o psicológico preparado para necessidade de cuidados, aí fica difícil.

É fato a percepção entre as enfermeiras da relação existente entre a obesidade e os fatores psicológicos. Cientificamente, as alterações psicossociais geradas podem se manifestar por passividade e submissão, preocupação excessiva com comida ou ingestão compulsiva, dependência, indicadores de dificuldades de adaptação social, bloqueio da agressividade, dificuldade para absorver frustração, insegurança, intolerância e culpa(11).

Entretanto, o obeso não necessariamente possui problemas psicológicos, sendo preciso desmistificar esta crença que é muito utilizada como explicação para o 
excesso de peso. Mas, deve-se compreender que os obesos hospitalizados podem apresentar maiores níveis de sintomas depressivos, ansiedade, transtornos alimentares, de personalidade e distúrbios da imagem corporal $^{(8)}$.

O significado do paciente obeso como aquele que dá mais trabalho repercute no entendimento por parte da equipe de enfermagem no sentido do cuidar como um procedimento meramente técnico, o qual o paciente deve, como obrigação, estar preparado para recebê-lo. Para o Interacionismo Simbólico, esse significado pode se basear na premissa de que o mesmo tenha se originado a partir da interação social que o indivíduo estabelece com os outros pacientes em sua rotina ${ }^{(9)}$.

Isso nos remete ao fato de que, na verdade, a enfermagem deve procurar entender os sintomas psicológicos que podem ser apresentados pelo paciente obeso e, assim, prestar apoio e escuta ao mesmo, considerando esta ação como parte inerente do seu trabalho sem, para isso, criticá-lo, como é evidenciado no subtema a seguir.

\section{A equipe de enfermagem reclama do paciente obeso}

De acordo com os entrevistados, reclamar do paciente obeso significa expressar insatisfação ao permanecer responsável pela assistência ao mesmo alegando fatores individuais que dificultam o trabalho e maior risco para o desenvolvimento de doenças ocupacionais:

Então, é um plantão que você vai ouvir muita reclamação: olhe o gordinho! Olhe, ninguém aguenta, chame mais alguém! (E2)

(...) todo mundo reclama: ah, eu não vou ficar com esse paciente; ah, eu não posso; tenho hérnia de disco; tenho varizes; tenho idade. Aí acha que cuidando daquele paciente ficamais cansada ou temsobrecarga maior. Então é reclamação geral. (E4)

O pessoal reclama mesmo, pois alegam que pode acarretar problemas de saúde para o profissional. (E6)

A literatura aponta que a equipe de enfermagem está entre as principais categorias sujeitas à exposição ocupacional relacionando-se com o fato de o grupo ocupar o maior número de trabalhadores de saúde e ter contato mais direto na assistência aos pacientes, e também pela frequência de procedimentos realizados ${ }^{(16-17)}$.

As falas das enfermeiras reforçam as informações supracitadas ao inserirem aspectos comuns de insatisfação. Isso permite a reflexão de que, devido às condições desfavoráveis existentes no ambiente hospitalar, os profissionais respondem a essa realidade através de posturas resistentes e até preconceituosas em relação ao cuidar, reforçando os significados de que o obeso é responsável pela existência do risco ocupacional, que dá mais trabalho, é cansativo e requer cuidados diferenciados $^{(9)}$.

Para o Interacionismo Simbólico, essas considerações são explicadas a partir da premissa de que os significados são manipulados por um processo interpretativo usado pela equipe, ao lidar com as situações que ela encontra em sua rotina, em relação ao indivíduo obeso. Apesar das dificuldades encontradas, as enfermeiras reconhecem que esse paciente necessita da assistência prestada pela enfermagem e, que para que isso aconteça de forma satisfatória, a equipe precisa de mobilização e de um objetivo comum, como pode ser visto no tema a seguir.

\section{Cuidar de um paciente obeso exige trabalho em equipe}

De acordo com as entrevistas, cuidar de um paciente obeso significa reconhecer a necessidade de trabalhar em equipe; significa ajudar um ao outro, juntar as mãos, mobilizar, formar uma comitiva que se dedica a agir para o alcance de determinado objetivo em comum, o que possibilita a troca de conhecimento e a agilidade no cumprimento de metas:

A gente precisa resolver o que precisa ser resolvido. É juntar as mãos e trabalhar em equipe. (E1)

Para cuidar dele precisamos de uma comitiva, de mobilização da equipe. (E5)

Com um paciente de $180 \mathrm{~kg}$, como você faz? Se tua colega não quer ajudar, se não trabalhar em equipe, é complicado. (E3)

Assim como as enfermeiras se reportaram, a definição de trabalho em equipe é a de um grupo de indivíduos que interagem de maneira adaptativa para cumprir um objetivo comum. Esta intervenção promove mudança das práticas de saúde que assegura uma assistência que responda tecnicamente às necessidades dos usuários do serviço. Para a equipe alcançar um grau de integração, é preciso que seus componentes realizem uma articulação que requer que o profissional coloque em evidência as conexões existentes entre as intervenções executadas pelos demais integrantes da equipe ${ }^{(16)}$.

Segundo o Interacionismo Simbólico, a atividade grupal considerada pelos sujeitos fundamenta-se no comportamento cooperativo que surge por cada pessoa da equipe em perceber a intenção dos outros e construir a 
sua resposta baseada naquela intenção(9). Desse modo, percebe-se que os significados das enfermeiras deveriam ser reagrupados para uma mesma intenção, que consiste no cuidar. Entendemos, portanto, que se cada pessoa colocar em prática, isto é, ter sempre uma resposta ao seu significado verificado nesta pesquisa, este objetivo poderá ser modificado de maneira positiva ou negativa.

Sintetizando o modelo de significação construído pelas participantes, entendemos que as enfermeiras, ao receberem pacientes obesos no seu setor de trabalho reparam como esses pacientes ultrapassaram seus limites, encontrando-se visivelmente em descompasso com os padrões de normalidade de peso, e atribuem esse "a mais" a excessos praticados a vida toda. Atribuindo a "culpa" pelo excesso de peso aos indivíduos, as enfermeiras acabam por desenvolver certa "rejeição" a esses pacientes.

Além disso, as enfermeiras já imaginam que irão ter mais trabalho porque sabem que os pacientes obesos irão exigir uma estrutura de cuidado que o hospital não possui, como mais funcionários de Enfermagem com quem se possa dividir o esforço necessário e equipamentos que permitam mobilizar o sujeito sem comprometer a saúde dos profissionais. $O$ fato de não contar com esses elementos passa a significar, para as estudadas, um problema a ser administrado por elas próprias no sentido de conduzir a equipe para cuidar por meio do improviso, o que pode gerar insatisfação para elas e para os pacientes.

\section{REFERÊNCIAS}

1. Lois K, Young J, Kumar S. Obesity: epiphenomenon or cause of metabolic syndrome? Int J ClinPract. 2008;62(6):932-8.

2. Associação Brasileira para o Estudo da Obesidade e da Síndrome Metabólica. Diretrizes brasileiras de obesidade 2009/2010. 3st ed. São Paulo: AC Farmacêutica; 2009. 19 p. 3. Agra G, Henriques ERM. Vivência de mulheres que se submeteram à gastroplastia. Rev. Eletr. Enf. [Internet]. 2008 [cited 2009 dez 31];11(4):982-92. Available from: http://www.fen.ufg.br/revista/v11/n4/v11n4a24.htm 4. Santos JP, Souza MCBM, Oliveira NF. Criança obesa, adulto hipertenso? Rev. Eletr. Enf. [Internet]. 2011;13(1):70-7. Available from: http://dx.doi.org/10.5216/ree.v13i1.6346. 5. Gigante DP, Moura EC, Sardinha, LMV. Prevalence of overweight and obesityand associated factors, Brazil, 2006.Rev Saúde Pública. 2009;43(2):83-9. Available from: http://www.scielo.br/pdf/rbepid/v14s1/a16v14s1.pdf 6. Mendonça MRT, Silva, MAM, Rivera ET AL. Prevalência de obesidade em Crianças e adolescentes da cidade de Maceió.Rev Assoc Med Bras. 2010;56(2):192-6. Available from: http://www.scielo.br/pdf/ramb/v56n2/a18v56n2.pdf 7. Marcelino LF, Patrício, ZM. A complexidade da obesidade e o processo de viverapós a cirurgia bariátrica: uma questão de saúde coletiva.Ciência \& Saúde Coletiva.2011;16(12):47674776.Availablefrom: http://www.scielo.br/pdf/csc/v16n12/25.pdf

\section{CONCLUSÃO}

Para as enfermeiras estudadas, o ser obeso significa alguém que se encontra além da sua capacidade física e que, por isso, não é saudável. Por ser uma pessoa tão acima, os sujeitos compreendem que o mundo não se encontra adaptado para os obesos, o que, no âmbito hospitalar, é representado pela carência de recursos humanos e materiais adaptados para esse tipo de paciente.

É, pois, diante dessa realidade, que algumas enfermeiras ressignificam o cuidar dessas pessoas como sendo mais trabalhoso em relação aos demais pacientes, significando-o até como um problema, mas que pode ser solucionado por meio do trabalho em equipe.

Considerando-se que a alta prevalência da obesidade tem elevado o quantitativo de sujeitos que buscam os serviços de saúde para se tratar e que uma das alternativas é algum tipo de cirurgia bariátrica, é esperado que a frequência desses pacientes também se eleve. Os resultados da pesquisa mostraram que o significado negativo construído acerca do paciente obeso pode interferir nas práticas de cuidar, sendo que é responsabilidade ética da equipe de enfermagem não permitir que isso aconteça.

Apesar da sobrecarga de serviço considerada nas entrevistas, a equipe de enfermagem precisa considerar o ser humano em sua totalidade no processo de cuidar. Assim, é possível que os significados atribuídos pelas enfermeiras nesta pesquisa possam ser modificados positivamente, contribuindo para um cuidado de Enfermagem ao obeso, livre de discriminações.

8. Oliveira MS, Lima EFA, Leite FMC. Perfil do paciente obeso submetido à cirurgia bariátrica. Rev Cogitare Enferm. 2013;18(1):90-4. Available from:

http://ojs.c3sl.ufpr.br/ojs2/index.php/cogitare/article/view/3131 $\underline{2 / 20019}$

9. Blumer H. Symbolic Interactionism. Los Angeles: Berkeley P; 1969.

10. Wanderley EN, Ferreira VA. Obesidade: uma perspectiva plural. Rev. Ciên \& Saú Colet. 2010;15(1):185-94.Available from:

http://www.scielo.br/scielo.php?pid=S141381232010000100024

\&script $=$ sci arttext

11. Tanaka DS, Peniche ACG. Assistência ao paciente obeso mórbido submetido à cirurgia bariátrica: dificuldades do enfermeiro. Acta Paul. Enferm. 2009;22(5):618-23.Available from: http://www.scielo.br/pdf/ape/v22n5/04.pdf 12. Portaria no 492, de 31 de agosto de 2007. Institui diretrizes para a atenção à saúde com vistas à prevenção da obesidade e assistência ao portador de obesidade. Avalaible from: http://www.sbcb.org.br/legislacao.asp?menu=3. 13. Oh S, Kim KS, Chung YS, Shong M, Park SB. Anti-obesity agents: a focused review on the structural classification of therapeutic entities. Curr Top Med Chem. 2009;9(6):466-81. 
14. COFEN. Resolução COFEN-311/2007. Aprova a Reformulação do Código de Ética dos Profissionais de Enfermagem. Rio de Janeiro (Brasil): COFEN; 2007.

15. Carvalho V. Por uma epistemologia do cuidado de enfermagem e a formação dos sujeitos do conhecimento na área da enfermagem: do ângulo de uma visão filosófica. Esc. Anna Nery. 2009 [cited 2013 Nov 21];13(2):406-414. Available from: http://dx.doi.org/10.1590/S1414-81452009000200024.

16. Regis LFLV, Porto I.S. Necessidades humanas básicas dos profissionais de enfermagem: situações de (in)satisfação no trabalho. Rev Esc Enferm USP. 2011;45(2):334-41.Available from: http://www.scielo.br/scielo.php?pid=S0080$62342011000200005 \&$ script $=$ sci arttext

17. Grejanin DKM, Pezzo TH, Nastri V, Sanches VPP, Nascimento DDG, Quevedo MP. As percepções sobre o "ser obeso" sob a ótica do paciente e dos profissionais de saúde. Rev Bras Cresc e desenvolvimento hum. 2007;17(3):37-47. Available from: www.revistas.usp.br/jhgd/article/download/19846/21919.

Artigo recebido em 16/10/12.

Aprovado para publicação em 11/11/13

Artigo publicado em 31/03/2014. 